\title{
Knowledge Regarding HIV/AIDS among Nepalese Army
}

\author{
Roy $\mathrm{RK}^{1}$, Roy $\mathrm{DK}^{2}$, Ghimire $\mathrm{S}^{3}$, Bist $\mathrm{A}^{3}$, Maharaj $\mathrm{A}^{4}$
}

\section{ABSTRACT}

Introduction: A global pandemic threat HIV/AIDS is also matter of concern of developing countries like Nepal where the first case was identified in July 1988 and later became epidemic and then concentrated epidemic among risk group for HIV. Several studies reflected HIV is associated to many factors, Literacy and Socio-economic conditions being at the highest rank. Members of Nepal army are generally with less educational background and few with higher educational status are at higher post. Thus knowledge regarding HIV/AIDS among this group need to be assessed. Aims: The overall objective of our study was to assess knowledge regarding HIV/AIDS among Nepal army in Banke district. Methods: A Cross-sectional descriptive study with population size of 146 Army was performed which covered the entire population of Shree Shreemehar Army Camp in Banke, starting from $18^{\text {th }}$ June to $27^{\text {th }}$ August, 2018. A pre-tested questionnaire containing structural, semi-structural and open ended questions were made as data collection tool. All the soldiers in Army camp were interviewed after receiving consent as an ethical clearance. Results: All 146 Army of our study were aware about HIV/AIDS mainly via mass media (83.56\%). 33 respondents still didn't know about availability of its treatment. Misconception about its complete cure and vaccination was seen in 12 and 39 respondents respectively. 58 respondents were found knowing about the free health services by government. 141 respondents knew certain things about prevention. 28 respondents admitted of having multiple sex partners and only 24 among them used preventive measure. Conclusion: Though all the respondents of our study had known about HIV/AIDS still they had misconception regarding its treatment and prevention. Many respondents do not even know about the free health services of government. Few of them still don't use preventive measure.

Keywords: HIV/AIDS, Nepal Army, Knowledge, Prevention, Misconception

\section{Authors:}

1. Mr. Roshan Kumar Roy

2. Dr. Deepak Kumar Roy

3. Mr. Sabal Ghimire

4. Mr. Ayush Bist

5. Dr. Anuranjan Maharaj

${ }^{1}$ Department of Community Medicine, Nepalgunj Medical College, Chisapani, Banke

${ }^{2}$ Department of Conservative Dentistry and Endodontics, Kathmandu Medical College and Teaching Hospital

${ }^{3}$ Nepalgunj Medical College, Chisapani, Banke

${ }^{4}$ Buddha Dental College, Patna

\section{Address for Correspondence:}

Mr. Roshan Kumar Roy

Department of Community Medicine

Nepalgunj Medical College

Chisapani, Banke

Email: link2roy@gmail.com

\section{INTRODUCTION}

Since the first case in United States in 1981, AIDS has spread throughout the world turning it a global pandemic. AIDS is a condition in which progression allows life-threatening opportunistic infections. An estimated 36.7 million people worldwide were living with HIV/AIDS at the end of 2016, And one million people died from AIDS-related illnesses in 2016 ,bringing the total number of deaths from AIDS-related illnessesto 35.0 million. Nepal started its policy response to the epidemic of HIV in 1995. The prevalence of HIV/AIDS in Nepal among adult population is estimated to be 0.23 which is considered "generalized and severe." By 2020, as of Government Policy, $90 \%$ of all people with diagnosed HIV infection will receive sustained antiretroviral therapy, and 90\% of all people receiving antiretroviral therapy will have viral suppression. ${ }^{1,16}$ More than four in every five new infections are transmitted through sexual transmission in Nepal. Drugs abusers, MSM, and female sex workers are at higher risk in Nepal. Labour migrants, and clients of female sex workers transfer infections from high to low risk population. As the selection of Army in our country is not based on higher education qualification, most of them are school drop outs and very few educated are at higher posts. Army are trained for long time period away from their family, As a result they are indulge in high sexual activities for pleasure to get relieved of related training stress. ${ }^{16}$ This study is focused on assessing knowledge regarding HIV/AIDS among Nepal Army 


\section{METHODS}

This study was conducted based on descriptive cross sectional study design, data was collected only once and there was no follow up done. This study was basically focused on assessing the knowledge regarding HIV/AIDS among Army youths in Shree Shreemehar Army Camp, Banke district. Army were interviewed using questionnaire having structured and semistructured also open ended questions. All the Army residing in the camp were interviewed. Collected primary data were later tabulated and analyzed using cross tabulation and descriptive calculations. Study was started in 18th June 2018. Validity and reliability of questionnaire were checked by interviewing $30 \%$ of real study population. Nepali language was used in the questionnaire for better response. All the collected information was assessed using MS-EXCEL and SPSS version 22 for descriptive analysis. Informed consent was taken from each Army youth. Analyzed data were thus presented in the form of tables and charts and interpreted accordingly.

\section{RESULTS}

All 146 respondents of our study have heard about HIV/AIDS.

\begin{tabular}{|lcc|}
\multicolumn{1}{c}{ Media } & Number & Percentage \\
\hline T.V/Radio & 122 & $83.56 \%$ \\
\hline Family/Friends & 59 & $40.41 \%$ \\
\hline Newspaper/Books & 99 & $67.80 \%$ \\
\hline Community Field Programme & 82 & $56.16 \%$ \\
\hline Others & 0 & $0 \%$ \\
\hline
\end{tabular}

Table I: source of information regarding HIV/AIDS

Table above shows that highest number of respondents i.e. 122(83.56\%) have heard about HIV/AIDS via T.V/Radio.

\begin{tabular}{|lcc|}
\multicolumn{1}{c}{ Knowledge } & Number & Percentage \\
\hline $\begin{array}{l}\text { It is a life threatening } \\
\text { disease }\end{array}$ & 60 & $41.09 \%$ \\
\hline $\begin{array}{l}\text { Communicable disease } \\
\text { Sexually Transmitted } \\
\text { Disease }\end{array}$ & 89 & $60.95 \%$ \\
\hline Bad character disease & 118 & $80.82 \%$ \\
\hline Not curable disease & 37 & $7.5 \%$ \\
\hline Disease of Sex workers & 08 & $25.34 \%$ \\
\hline Disease of drug abusers & 05 & $5.4 \%$ \\
\hline $\begin{array}{l}\text { Brought by Foreign } \\
\text { Workers }\end{array}$ & 10 & $3.4 \%$ \\
\hline Bombay disease & 04 & $6.8 \%$ \\
\hline Others & 04 & $2.7 \%$ \\
\hline
\end{tabular}

Table II: Knowledge regarding HIV/AIDS

Table above shows that out of 146 respondents, highest number of respondents i.e. 118(80.82\%) know that HIV/AIDS is a sexually transmitted disease.

\begin{tabular}{|lcc|}
\hline \multicolumn{1}{|c}{ Source of transmission } & Number & Percentage \\
\hline Touching & 0 & $0 \%$ \\
\hline Handshaking & 0 & $0 \%$ \\
\hline Eating Together & 0 & $0 \%$ \\
\hline Unsafe sexual contact & 123 & $84.24 \%$ \\
\hline Sharing Syringe & 85 & $58.21 \%$ \\
\hline Sharing of clothes \& utensils & 05 & $3.4 \%$ \\
\hline Sleeping together & 04 & $2.7 \%$ \\
\hline Kissing & 16 & $10.95 \%$ \\
\hline Mosquito bite & 05 & $3.42 \%$ \\
\hline Vertical transmission & 60 & $41.09 \%$ \\
\hline Multiple sexual partners & 22 & $15.06 \%$ \\
\hline Others & 0 & $0 \%$ \\
\hline
\end{tabular}

Table III: Knowledge about Mode of Transmission

Table above shows that out of 146 respondents, highest number of respondents i.e.123 (84.24\%) think that HIV/AIDS transmits by unsafe sexual contact.

Possibility of treatment

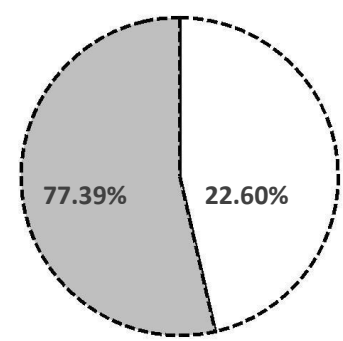

Yes(113) It It No(33)

Figure 1: Possibility of Treatment

Pie Chart above shows that out of 146 respondents, 113 (77.39\%) believe that the treatment is possible for HIV/ AIDS while remaining $33(22.60 \%)$ do not believe so.

\begin{tabular}{|lll|}
\hline \multicolumn{1}{c}{ Place } & Number & Percentage \\
\hline District level hospital & 43 & $38.05 \%$ \\
\hline Primary health center & 03 & $2.65 \%$ \\
\hline Zonal hospital & 19 & $16.81 \%$ \\
\hline Medical college hospital & 06 & $5.30 \%$ \\
\hline Private hospital & 02 & $1.76 \%$ \\
\hline Polyclinics & 13 & $11.50 \%$ \\
\hline Community hospital & 15 & $13.27 \%$ \\
\hline All health centers & 14 & $12.38 \%$ \\
\hline Multi-facilitated tertiary and & 63 & $55.75 \%$ \\
\hline expensive hospitals & & \\
\hline
\end{tabular}

Table III: Availability of Treatment 
Table above shows that out of 113 respondents, highest number of respondents i.e. 63(55.75\%) believe that its treatment is available at Multi-facilitated tertiary and expensive hospitals.

\section{Information about Free Government Health Service for HIV/ AIDS}

Out of 146 respondents, 58(39.72\%) know that Government of Nepal provides free services for this disease while remaining $88(60.27 \%)$ do not know about it. Out of 58 informed respondents, $30(51.72 \%)$ responded that Government of Nepal provides free health services for HIV/AIDS in District Level hospitals.141(96.57\%) out of 146 responded that HIV/ AIDS can be prevented while $5(3.42 \%)$ were unknown about the preventive measures.

$\begin{array}{lcc}\text { Preventive Measures } & \text { Numbers } & \text { Percentage } \\ \begin{array}{l}\text { Safe Sexual Contact } \\ \text { Safe blood transfusion }\end{array} & 133 & 94.32 \% \\ \begin{array}{l}\text { Using Disposable syringes } \\ \begin{array}{l}\text { Isolation of person suffering from } \\ \text { disease }\end{array}\end{array} & 07 & 68.73 \% \\ \begin{array}{l}\text { Boycotting the person from } \\ \text { society }\end{array} & 0 & 56.73 \% \\ \begin{array}{l}\text { Eating Separately } \\ \text { Sleeping Separately }\end{array} & 08 & 0 \% \\ \text { Others } & 05 & 0 \% \\ \end{array}$

Table IV: Preventive Measures

Table above shows that out of 141 respondents, highest number of respondent i.e. 133 (94.32\%) were well known that HIV/AIDS can be by prevented by Safe Sexual Contact. However $08(5.60 \%)$ said that the infected persons should eat separately.

\section{Information about PMTCT}

Out of 146 respondents, 56(38.35\%) had known about Prevention of Mother to Child Transmission (PMTCT) while 90(61.64\%) had no idea about it.

\section{Knowledge regarding treatment possibility and vaccination}

Out of 141 respondents, 12(8.21\%) said that HIV/AIDS could be treated while rest $134(91.78 \%)$ were unknown about its treatment. Also $39(26.71 \%)$ had misconception that vaccine is available for HIV/AIDS while 107(73.28\%) agreed that vaccination is not available.

\section{Attainment in trainings}

Only 40(27.39\%) respondents had taken training/health education class related to HIV/AIDS via sources such as: School teachers, Health Posts, District Health Office (DHO) etc.

\section{Sexual behaviour}

Out of 146 respondents, 28(19.17\%) admitted that they had sex with multiple partners while rest $118(80.82 \%)$ did not admit so.

\section{Prevention from HIV/AIDS and STDs}

$24(85.71 \%)$ out of 28 respondents practicing multiple sex were adopting preventive measures of STDs while 04(14.28\%) were not. Condom was found to be the only preventive measure used by all.

\section{DISCUSSION}

All of the 146 respondents of our study have heard about HIV/AIDS while a similar kind of research conducted by Mr. Chetan Nidhi Wagle, NHRC, 2009 among 251 policemen of KathmanduMetropolitan showed the average of $73 \%$ only had knowledge of HIV. ${ }^{2}$ There was another research on "knowledge of HIV/AIDS among adolescence at intellectual academy in kumarigal-7, Tushal, kathmandu, Nepal" by Mrs. Gayatri Rana which showed that only $66 \%$ of adolescence hadknowledge that HIV/AIDS is communicable disease. ${ }^{3}$ Also a research conducted by Dr. Shikha Trivedi reported that $88.3 \%$ of students had heard about HIV/AIDS. ${ }^{4}$ Highest number of respondents i.e. $122(83.56 \%)$ have heard about HIV/AIDS via T.V/Radio in our research. And for a similar type of research conducted by Mr. Chetan Nidhi Wagle, NHRC, 2009 on "knowledge on HIV \& AIDS and sexual behaviours among the Nepal police of Kathmandu metropolitan, Nepal" showed Radio/T.V was the major source for only $59 \%$ individuals. ${ }^{2}$ Our study reflected that $118(80.82 \%)$ respondents knew that HIV/AIDS is a sexually transmitted disease among which $84.24 \%$ people had knowledge of transmission via unsafe sex, $58.21 \%$ had idea regarding transmission by contaminated blood and $41.09 \%$ knew about vertical transmission. While a research by Mr. Tulsi Ram Bhandari showed more than two-third respondents had knowledge on transmission, from which the highest (85\%) had responded "unsafe sex", 72\% through "contaminated blood", $67 \%$ via "verticaltransmission" and remaining $27 \%$ were unaware. ${ }^{5}$ On the other hand another research done by $\mathrm{M}$ Bharati, L Bharati reported $94.7 \%$ individual knew HIV transmits via needle sharing. ${ }^{6}$ Also a research by $\mathrm{G}$ Rana on adolescents reflected that $90 \%$ of HIV transmission is due to unprotected sexual contacts. ${ }^{3}$ Our research reflected, $113(77.39 \%)$ of the respondents know that the treatment is possible for HIV/ AIDS. While another research by Sandeep Sachdeva, Jagbir S. Malik, Ruchi Sachdeva, Tilak R. in Nigeria and Delhi showed proportion of respondents who were awared about existence of anti-retroviral drugs for HIV/AIDS were $52.60 \%$ and $28.6 \%$ respectively. ${ }^{7}$ In another research by $\mathrm{N}$ Pandey, majority (37\%) of respondents said that the drug for the treatment of HIV/ AIDS is not available, (31.5\%) said there is availability of drug and $(31.5 \%)$ did not know about the drug. ${ }^{8}$ In this study, 113 responded that the treatment of HIV/AIDS is available, of which 63 responded treatment to be limited in Multi-facilitated tertiary and expensive hospitals. 58 i.e. $39.72 \%$ respondents knew Government of Nepal provides free health services for 
HIV/AIDS. Dr. Khem Bahadur Karki on an interview under the topic - HIV/AIDS, declining in Nepal taken by Pratik Rimal which was published in My Republica, $1^{\text {st }}$ December 2017; said that "The government is focused on curative measures, but a lot more needs to be done on preventive measures in order to change behaviours. The government is well able to fund to provide free treatment. We just need proper planning. 9,16 $141(96.57 \%)$ out of 146 individuals in our study responded that HIV/AIDS can be prevented. Only 24(85.71\%) of 28 respondents having multiple sex partners, were adopting cond om only as preventive measures for HIV and STDs. On a research by POLICY Project Nigeria, approximately $12 \%$ of the respondents knew of no ways to prevent HIV/AIDS. Some of the commonly cited modes of prevention of HIV included use of condoms (72.7\%), fidelity (59.7\%), and not receiving injections with shared or re-used needles (38.6\%). Abstinence was mentioned by only slightly more than $10 \%$ of all respondents. Some of the misconceptions or incorrect responses included prevention by not kissing (10.3\%). ${ }^{10}$ Another research conducted by Awasthi $\mathrm{KR}$, Adefemi $\mathrm{K}$, Tamrakar $\mathrm{M}$ reported that unprotected sex is practiced by more than $70 \%$ of the truck drivers with studies showing that more than two thirds of the drivers have had experiences of having sex with a sex worker, at least once, during the course of their travels. ${ }^{11} 133(94.32 \%)$ respondents in our study were well known that HIV/AIDS can be by prevented only by Safe Sexual Contact. However only 08(5.6\%) said that the infected persons should not eat together with others. The HIV prevention methods were reported to be condom use, no sexual contact, self -control, avoid sex workers and multiple sex partners as perthe research conducted by Karoline Moon Department of Health Policy and Administration. ${ }^{12}$ Further another comparative research was done by Elna van der Ryst et alshowed highpercentage of respondents i.e. $57.1 \%$ mentioning that people living with AIDS should not haveright to normal sex lives. ${ }^{13} 56(38.35 \%)$ respondents had known about Prevention of Mother toChild Transmission (PMTCT) in our study. Similar study by Dr. Shikha Trivedi shows only $23.4 \%$ cited mother to baby as routes of transmission of HIV. ${ }^{4} 8.21 \%$ out of 146 respondents said that HIV/AIDS could be treated completely while $91.78 \%$ were unknown about its treatment. Also, 39(26.71\%) had misconception that vaccine is available for HIV/AIDS while $107(73.28 \%)$ agreedthat vaccination is not available. A research conducted by Jaiswal S, Magar BS et al reflected that $46.2 \%$ of total respondents knew that vaccine is yet not available for HIV/AIDS. ${ }^{14,16}$ Dr. Shikha Trivedi on her research also reported that $9 \%$ and $11 \%$ of respondents believe that there is cure and vaccine for AIDS respectively ${ }^{4}$. Out of 146 respondents, 28(19.17\%) admitted that they had sex with multiple partners while rest $118(80.82 \%)$ did not admit so. In a similar research by Karna Bahadur Oli and Mahendra Maharjan on their research reflected that about $16 \%$ of the participants had expressed their practice of sexual relationship outside more than once, which signifies vulnerability to HIV infection. ${ }^{15,16}$

\section{LIMITATIONS}

Assessment of Knowledge regarding HIV- AIDS among Army group, in this study came up with certain limitations as well, such as; the sample were taken from only one army camp located in Sumsergunj, also it would reflect better generalization if the sample size would be more large. Also, all the factors and determinants are not assessed in this study. Better correlation could have been formed (Correlation Coefficient has not been used) between several factors and the knowledge level among Army people. Besides, physical limitations related to fundings and infrastructural support may have definitely enhanced the study.

\section{CONCLUSION}

Out of 146 respondents in our study, all have heard about HIV/AIDS of which $83.56 \%$ have heard via T.V/Radio and among them, $80.82 \%$ know that it is a Sexually Transmitted Disease. Along that $84.24 \%$ responded that this disease is transmitted via unsafe sexual contact and only $113(77.39 \%)$ of 146 respondents knew that treatment of this disease is possible and among them, 55.75\% knew that the treatment of HIV is available only in multi-facilitated tertiary and expensive hospitals. Out of 146 individuals, only $39.72 \%$ knew that Government of Nepal provides free health services and among them only $51.72 \%$ responded the free services are available only in District level hospitals. Regarding prevention, 94.32\% knew that prevention of HIV is possible by safe sexual behavior, also 38.35\% knew about Prevention of Mother to Child Transmission. $73.28 \%$ of the total respondent was aware regarding absence of any vaccinations for HIV. Only $27.39 \%$ have taken any formal trainings/health educational classes regarding HIV. Besides knowledge, only 28 individuals accepted having multiple sex partners. Among them, 24 admitted using preventives measures and condom was found to be the only preventive measure used by all for prevention of HIV, AIDS, and STIs.

\section{REFERENCES}

1. Department of Health Services, Nepal. Annual Report. 2073/74;23:175-177

2. Wagle C N. A Research Report On Knowledge On HIV \& AIDS And Sexual Behaviors Among The Nepal Police Of Kathmandu Metropolitan, Nepal. NHRC library. 2009.

3. Rana G. Knowledge Of HIV/AIDS Among Adolescence At Intellectual Academy In Kumarigal-7, Tushal, Kathmandu, Nepal. 2014; 4(10): 39-41

4. Trivedi S. HIV/AIDS Awareness Level in Secondary Schools of India after Twenty Seven Years. IOSR-JHSS.2014 Mar; 19(03):71-75

5. Bhandari TR. Knowledge on HIV/AIDS among Secondary Level School Students in Kathmandu, Nepal. JHAS.2010;1(01):1619

6. Bharati $M, L$ Bharati .A study on knowledge of HIV/AIDS among adolescents of higher secondary school in Jajarkot district of Nepal. JCMC. 2014; 4(3):43-45

7. Sachdeva R, Sachdev T R, Sachdeva S, Malik J S. HIV/ AIDS knowledge among first year MBBS, Nursing, 
Pharmacy students of a health university, ndia.JFCM.2011 Dec;18(03):155-158

8. Pandey N. Knowledge of Pregnant Women Regarding HIV/ AIDS. JCMC. 2013; 3(5): 18-21

9. Rimal P. Hiv/Aids Declining In Nepal.https://myrepublica. nagariknetwork.com/news/hiv-aids-declining-in-nepal. 2017 December 01.

10. Policy Project Nigeria. Knowledge, Attitudes, and Sexual Behaviour among the Nigerian Military Concerning HIV/AIDS and STDs. AFPAC. 2002 Sep;01:20

11. Awasthi KR, Adefemi K, Tamrakar. HIV/AIDS: A Persistent Health Issue for Women and Children in Mid and Far Western Nepal.KUMJ.2015; 20(20)

12. Karoline Moon Department of Health Policy and Administration. Knowledge, Perceptions, Attitudes, and Practices of HIV/AIDS: A Comparative Study of Behavior Change in Commercial Sex Workers and Truck Drivers in the Dindigul and Coimbatore Districts of Tamil Nadu, India. UNCCPID.2002 May;06:21-23

13. Elna van der Ryst, Gina Joubert, Franois Steyn, Christo Heunis, Jo le Roux, Carolyn Williamson. HIV/ AIDS - Related Knowledge, Attitudes A N D Practices Among South African Military Recruits.SAMJ.2001 July;91(07):587-591

14. Jaiswal S, Magar BS, Thakali K, Pradhan A, Gurubacharya DL. HIV/AIDS and STI Related Knowledge, Attitude and Practice among High School Students in Kathmandu Valley. KUMJ. 2005;03( 09): 69-75

15. Oli B K, Maharjan M. HIV/AIDS in Migrant People of Dang District of Nepal. JIST. 2014; 19(2): 71-75

16. Roy R K, Roy D K, Ghimire S, Bist A. Knowledge regarding HIV/AIDS Among Armed Police Force Nepal.JKMC.2018; Vol 7 (4): 180-184 